\title{
ECONOMIC SITUATION AFTER COVID-19 - THE POLICY TRILEMMA
}

\author{
Iulian GOLE ${ }^{a *}$, Victor Adrian TROAC $\breve{A}^{b}$, Ciprian ROTARU ${ }^{c}$, Svetlana Platagea GOMBOS ${ }^{d}$, \\ Victor Marian DUMITRACHE ${ }^{e}$
}

${ }^{a},{ }^{b},{ }^{c},{ }^{d},{ }^{e}$ Bucharest University of Economic Studies, Romania

DOI: $10.24818 / \mathrm{IMC} / 2020 / 05.19$

\begin{abstract}
After almost five months of uncertainties, starting with the medical sectors, continuing with sports, tourism, aviation, conference, etc. we are still in the phase of asking how to deal with the Covid-19 pandemic and looking for answers. Each person is asking herself how to do and each government what policy to adopt. If the first observation to make about this pandemic is that it affects all the states of the planet, the second is that the responses provided by these states are extremely diverse, as are the results. The reason for this diversity lies in a "triangle of impossibility". The expression, well known to economists, originally refers to the difficulty of managing a country that wishes to manage a fixed exchange rate, monetary autonomy, and free capital mobility at the same time. It looks like the world is today in the same complicate situation; therefore, we believe is adequate to think about the difficulty of public management of the pandemic as an impossible trinity. By the means of descriptive and comparative analysis, the paper reveals the similitudes between the macroeconomic model Mundell-Fleming and recovering options available for governments after a pandemic crisis.
\end{abstract}

KEYWORDS: economic crisis, government policies, pandemic, trilemma.

\section{INTRODUCTION}

The original model of the trilemma, according to Mundell-Fleming 1960 and presented by various authors (Tetsuya, 2000; Beck, \& Prinz, 2012) in their researches, suggests that a country, who wishes to take fundamental decisions about international monetary policy, has only three options: to set a fixed currency exchange rate, to accept a free capital flow and an independent monetary policy. The problem is that no matter which decisions may be taken at a given time, always there is one of three which cannot be controlled.

a) In the first scenario, a country can choose to have a fixed exchange rate with some partners and free flow of capital with others but consequently this would create currency arbitrage so independent monetary policy cannot be achieved.

b) The second situation is if a country decides to a have free flow of capital with all foreign countries and an autonomous monetary policy. The problem is that there is not possible to have a free flow of capital and a fixed exchange rate at the same time.

c) The third option is if a country chooses to have a fixed exchange rate and an independent monetary policy. The problem is that it cannot have a free capital flow since the fixed exchange rate and free flow of capital excludes each other.

\footnotetext{
* Corresponding author. E-mail address: iuliangole@yahoo.com
} 


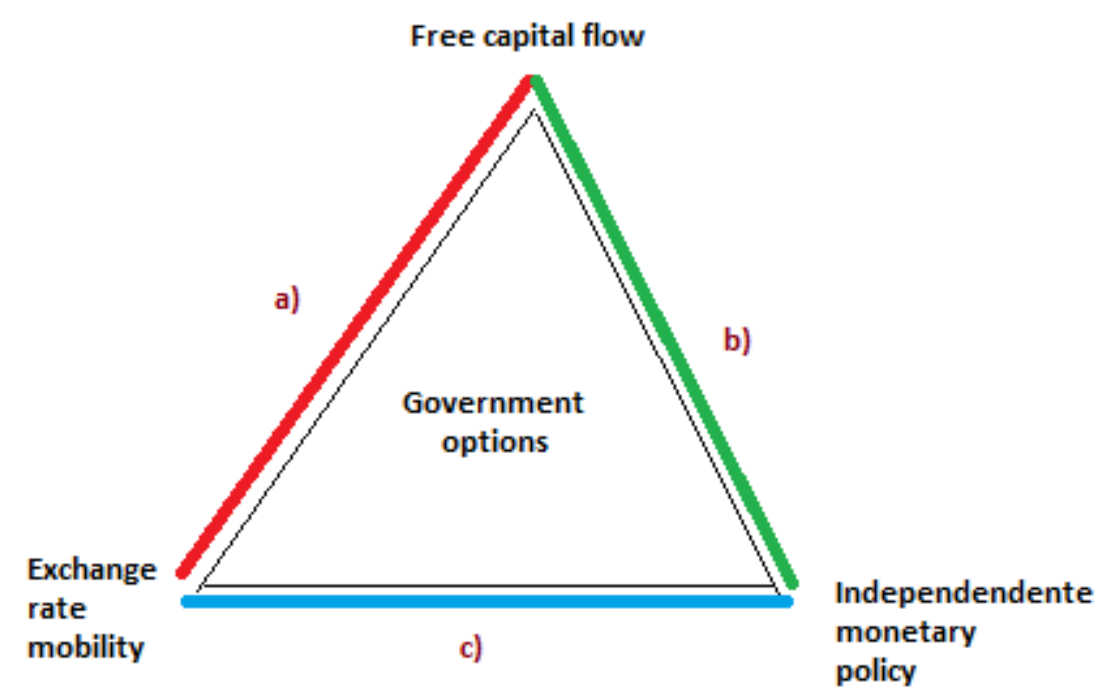

Figure 1. The policy trilemma

Source: Adapted from Mundell, Robert A, 1963

\section{THEORETICAL DILEMMA}

If we look closer to the situation after the Covid-19 pandemic, every government is confronting with similar circumstances since there are three main directions that a country may aim to reach but only two are feasible, the third one, as in the case of Mundell-Fleming trilemma, is impossible to get.

In today's situation, the reality is divided into three main directions. A country will try naturally to manage the three areas, as follows:

1. Optimal control of the pandemic in terms of health. This control is synthetically measured by the number of new people contaminated, the number of people found in critical situations in hospitals and, the number of deaths. All it is due to the virus during its period of activity which must be minimized.

2. Make the economic situation as it was before or make the pandemic have no economic impact. Despite the governments and other international institutions' efforts, we are all seeing a contouring worsening of the situation. If during the confinement, in Europe and U.S., many companies opted for technical unemployment, as a measure to help people, once the activity restarted, we could realize the real nature of the disaster - the level of activity diminished drastically, therefore the unemployment rate will probably reach to unseen levels, since the great recession.

3. Guarantee the greatest respect for public and individual freedoms. In democratic countries, restraining individual liberties is unacceptable, therefore governments have to take measures to protect the economy and the health of the population but at the same time, they have to make sure that human rights are respected.

Taking into consideration all the aspects, it seems impossible to achieve these three objectives simultaneously. Two can be achieved (logically might be feasible but practically is, of course, another matter) at the expense of the third, and we will explain in the next part why.

A. When we spoke about the first task from our analysis (optimal control of pandemic to protect general health) - most of the countries proved that is possible to do that by an absolute restriction of public movements and individual freedoms. Even the most affected countries by 
the virus eruption (China, Italy, Spain, U.S.) managed to stop the Covid-19 spreading by ensuring a complete rupture of the chains of transmission of the virus. If local authorities succeed, until a certain point, to keep intact some processes of production and distribution of goods and services, the individual freedoms of people were completely ignored.

B. If we considering the second objective of authorities, to maintain the level of the economy as before, it means that the individuals' freedom are respected so people can move freely (to move, work and socialize) but this is coming with the price of failing the health security rules (social distance) and consequently the number of cases will explode in a logarithmic equation. It was the case of Sweden who decided to opt for a mass immunization but the international community condemned the decision and even local government accepted that the results were not those expected at the beginning. The United Kingdom tried in the very early the same strategy but they changed quickly after the prime minister got sick.

C. The public authorities can decide to focus on controlling pandemic evolution by measures of testing more people and opening more medical facilities for treatment but this will come with a cost. If at the same time they decide to preserve individual freedoms it means more people will be infected so supplementary costs in the final equation. Consequently, these two directions can be taken only in very reach countries (Switzerland for example) where even if the normal economic objectives are sacrificed at a huge cost in terms of lost production and less revenue for the public budget, they still can optimally do it because there is an important financial reserve to back-up the situation. As we said it may work in a very specific country where people can afford an economic loss for a certain time but not everywhere and in any case the economic loss is quite important.

If we want to represent graphically the government options, it should be looking like the next figure.

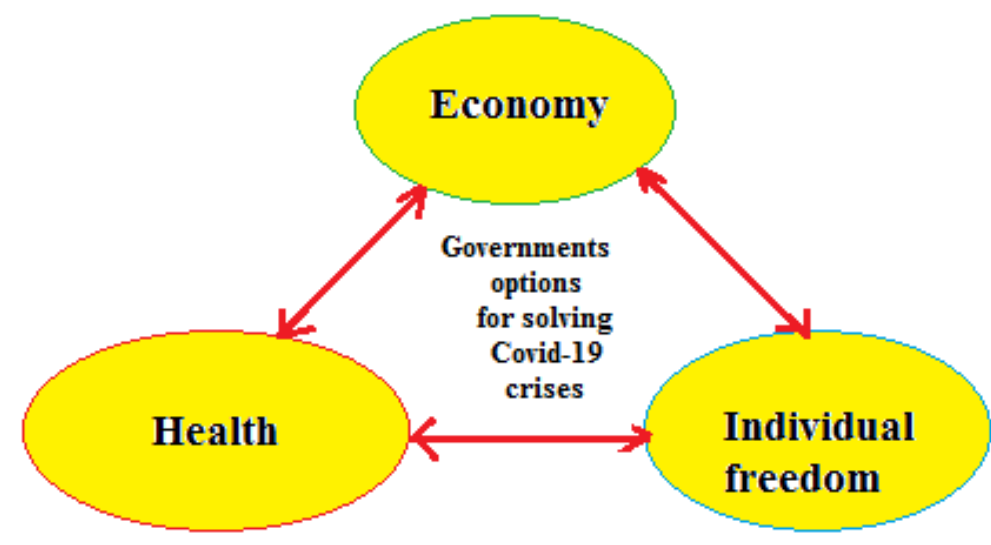

Figure 2. The government policy trilemma after the Covid-19 crisis

Source: own representation, based on Mundell-Fleming trilemma

This trilemma makes it possible to understand the three types of extreme strategy which frame the political choices of the leaders of the states of the planet.

Some states choose to sacrifice control of the pandemic so as not to limit citizens' freedom of movement and allow them to work "normally". This is the strategy that the Trump administration is tempted to apply in the United States. It is also the case in Brazil, where president Bolsonaro supported the idea that there is no need for confinement because the virus is not dangerous and the economy is more important (Sousa, 2020). The same decision was taken in Sweden but for a 
different reason: authorities deliberately assumed that population should go through a mass immunization, also known as "herd immunity" (Holly, 2020).

Authoritarian regimes are not concerned with liberties, even take advantage of the pandemic to increase the power of political authorities over their population and manage to contain the pandemic while limiting economic losses. It is the strategy of Hungary, Vietnam, and China. About NorthKorea it is not even worth mentioning.

Finally, a social-democratic state (like most European countries), with a tradition of strong social intervention, favours control of the pandemic and maximum respect for individual freedoms, but with the risk of negative economic outcomes.

The general confinement practiced in European countries (except a few) seeks to protect individuals from contamination but leaves them free to go out without strict control for their immediate personal needs while limiting as much as possible work-related outings. Combined with massive economic support measures, it guarantees them the maintenance of their income and their employment through general partial unemployment measures. It is therefore quite distant from the Chinese confinement, frankly coercive, or Dubai, where the exit is only possible once the authorization of the authorities has been obtained. The production losses caused by this policy of primacy of individual security - health and civic - over economic objectives are considerable.

\section{REALITY SITUATION}

These three cases are ideal-types. Any government must arbitrate between these three objectives and resolve this dilemma. Depending on its history, its economic solidity and the collective mentalities of the citizens, the policy carried out in a country can be identified by a point located inside the triangle, more or less close to the summits. Graphically, the triangle is determined by its peaks: H (Health), E (Economy), F (Freedom). The more the country is dictatorial, the closer the point chosen is closer to the HE segment (for example China and Hungary). The more libertarian the country is (the U.S.A. and U.K.), the closer the point is to the EF segment. The more "socialdemocratic" the country, the closer the point is to the HF (Switzerland and Sweden) segment.

The triangle of impossibility HEF is therefore a way of thinking about the diversity of public policies currently followed in the face of the onset of the pandemic and its massive global distribution. It is necessary to understand the puzzle facing all governments; few of them are in better situations but many being already in difficult circumstances even before Covid-19 appearance (France and Italy). The case of the British government, which began to rely on the strategy of collective immunity before coming to the policy of containment practiced by the continental European countries, is an example of this difficulty in choosing the right policy.

But the difficulty is not limited to this. Up to now, the reasoning has been static: it is assumed that the triangle is stable and known. However, the triangle of impossibility HEL deforms and at high speed. Covid-19 is a formidable virus not only by its lethality and indirectly by its ability to disrupt the economy and social organization, but also by the uncertainty that surrounds it. We have no precedent on which to base ourselves to organize our collective response to the pandemic and we know very little about the virus itself: its resilience, its capacity for mutation, the immunological properties associated with it. Any new information coming from the scientists who study it (virologists, epidemiologists, economists, sociologists, etc.) leads to a reassessment of the costs of optimal control of the pandemic, the means to be implemented to limit its spread, and the economic consequences. Likewise, we are gradually discovering the magnitude of the costs of emergency measures taken by governments. To use the graphic metaphor of the triangle of impossibility, it is deformed: the vertices move over time.

If we look at the Worldometers site about virus information we realize that there is a permanent change, worldwide, regarding the evolution of pandemic. At the moment when this paper was written, the distribution of cases was almost equally done if we take into consideration the size of 
the population. The fear is that some countries (India, Pakistan, and Bangladesh) are not yet at the point to exceed the pick, but rather at the beginning.

At the time when this paper was written (beginning of June 2020) there were more than 8.25 million cases in the world, and with a mean of 125000 new cases each day it is clear that governments cannot ignore the problem as they did it at the beginning. The U.S. is counting more than onequarter of the total cases, Brazil more than $11 \%$, and Russia $6.74 \%$.

Only these 3 countries count more than $42 \%$ of the total cases in the world. When we take into consideration that their leaders are frequently accused of populism and even sometimes dictatorship style of managing the country, maybe is not a coincidence the high number of cases in their countries. It looks that not giving any importance to civil liberties or pushing too hard on economic recovery doesn't bring too many results overall.

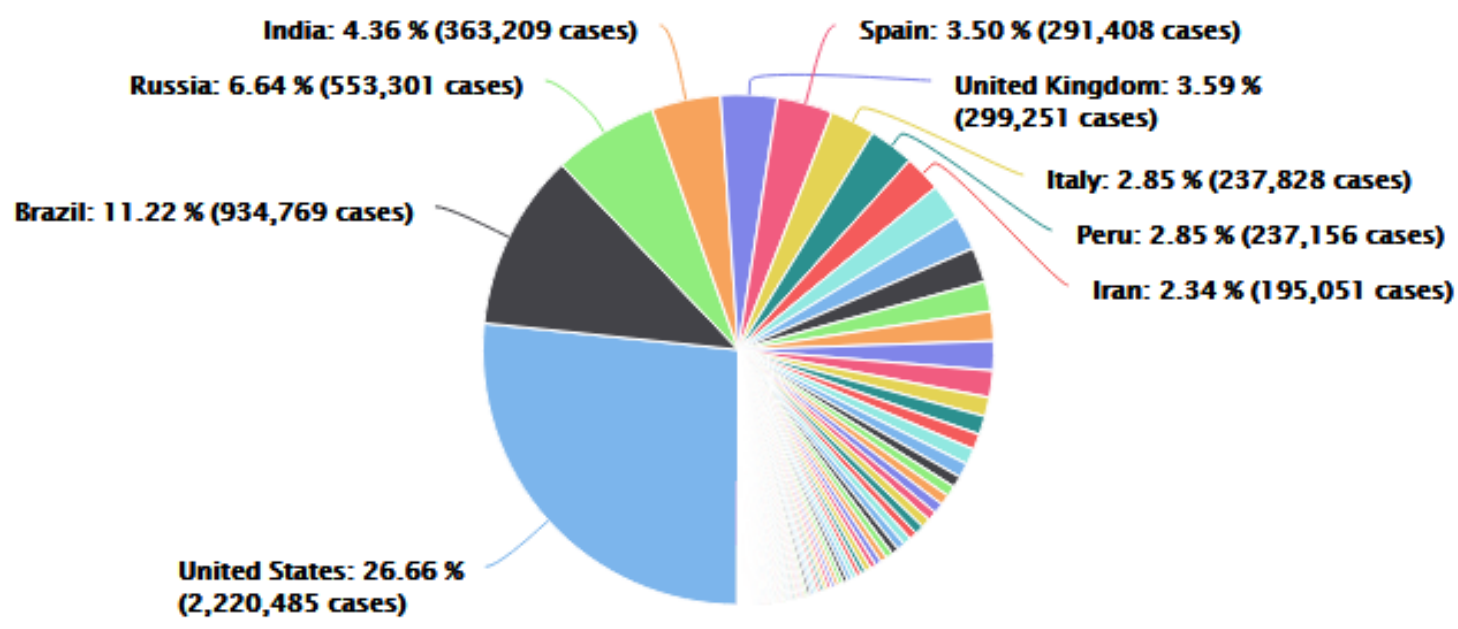

Figure 3. Countries' case distribution

Source: Worldometers, 2020

In the next graphic from Worldometers, we also can see the cumulative number of deaths, which is a very powerful indicator because it shows the real drama of the population. If when we count the new infestations, we certainly know that many people are asymptomatic and others are having minor medical problems, the shocking reality comes out when is about deaths. Looking at the graphic below, we can see that, despite the initial warning that the U.S. had from Italy and Spain, not taking any restrictions in terms of individual liberties or not putting the peoples' health as a priority for the government was a mistake.

It is known that medical system care in the U.S. is different from Europe, where it is perceived as a part of social responsibility. 43 million Americans are without insurance (Rhoades, Brown \& Vistnes, 2000) and this is certainly because the entrepreneurial medical system is the most expensive and also the most ineffective, from a social perspective.

We cannot know if this is the main reason why the U.S. has so many sick people and how many others are infected without being tested, but when we look at the graphic the situation raises some questions about the priorities settled by the administration. 


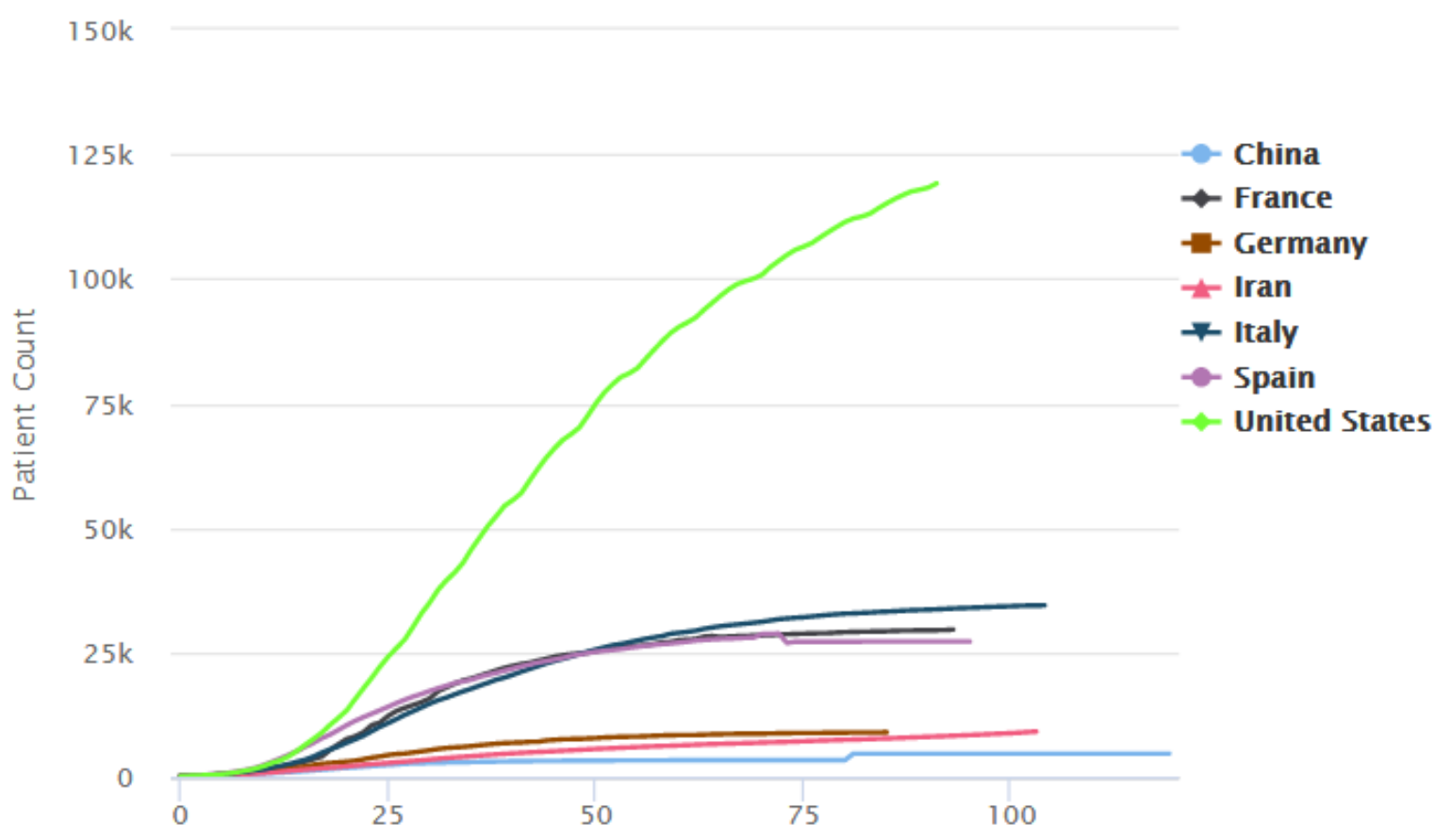

Figure 4. The cumulative number of deaths (by the number of days since 100 deaths) Source: Worldometers, 2020

It is not easy to choose which direction to go, since there is no previous experience and almost everywhere the elections are approaching and therefore the bill of the pandemic will be paid soon by politicians in power.

Arbitrating under these conditions is an obvious logical difficulty, for any government, especially because nobody was confronted with this situation in the past.

Faced with the moving trilemma that governments have to confront, we can put forward some conjectures:

* The public choices made one day have every reason to be modified in the following days.

None is a satisfactory ex-post.

* Public opinion, everybody can reasonably think that they do not master the complexity of the impossibility of trilemma and has the immediate impression of a great inconsistency on the part of their rulers, even great incompetence. Ultimately, they will have reason to be dissatisfied. The culprits will be quickly identified.

Analyzing this hypothesis we can imagine that the next period will be full of complex behaviors from the population side; also, governments will walk on sliding steps since nobody has the right to do mistakes and everybody needs to be helped to pass through this unseen situation.

\section{CONCLUSION}

The global chaotic reaction to the coronavirus pandemic has tested not only the government reaction but also the faith of even the most convicted internationals. All the countries, even the strongest in the world, have adopted travel bans, trying to produce everything they need inside the national territories, enforcing export controls, seizing merchandise of medical use, withholding or hiding information. The situation goes until even marginalizing the World Health Organization (WHO) and other multilateral institutions, as a response to governments' incapability or impossibility (as we saw) to find solutions. The pandemic put the democratic world and international community in a reality that nobody believed before. The tragedy is that this situation demonstrates the need for global cooperation and not failure. 
If hundred years ago the consequences of Spanish flu were, in a way dramatic but understandable since there were no cooperation and no international institutions, and the world was coming after years of war, today several multilateral institutions are acting to address public health emergencies but also to fight against negative economic and social effects. The reality is that the existence of such mechanisms has not prevented most states from taking contradictory decisions, and we proved why this situation is happening. There is no magical solution, out of three main areas (health, economy, and civil liberties) the governments have to choose mainly two directions in order to manage the crisis. International organizations are obviously less effective and in any case, when the election time is coming, the governments' leaders will respond for their actions or even innactions. Depending on their historical background (predilection for people's health, social liberties, or economic initiative), countries will be forced to pick two out of three possibilities from the trilemma triangle. Therefore some countries will recuperate after a pandemic in different ways, some of them because are having various resources at disposal but other because they have distinct options and policies.

\section{REFERNCES}

Beck, H. \& Prinz, A. (2012). The Trilemma of a Monetary Union: Another Impossible Trinity, Intereconomics, 47(1), 39-43.

Jeffrey, A., Rhoades, Vistnes, J., P. \& Brown, E. (2000). Health insurance status of the civilian noninstitutionalized population: 1998. Rockville (MD): Agency for Healthcare Research and Quality.

Holly, E. (2020). Sweden resisted a lockdown, and its capital Stockholm is expected to reach 'herd immunity' in weeks. CNBC. Retrieved August 10, 2020 from https://www.cnbc.com/2020/04/22/no-lockdown-in-sweden-but-stockholm-could-see-herdimmunity-in-weeks.html.

Matcha, D., A. (2003). Health Care Systems of the Developed World: How the United States' System Remain an Outlier. Santa Barbara (CA): Praeger Publisher.

Mundell, Robert, A. (1963). Capital mobility and stabilization policy under fixed and flexible exchange rates. Canadian Journal of Economics and Political Science 29 (4), 475-485.

Sousa, J. (2020). "I don't believe in collapse." Bolsonaro dismisses weaknesses in the Brazilian SNS, Jornal economico. Retrieved August 10, 2020 from https://jornaleconomico.sapo.pt/en/news/I-do-not-believe-in-the-collapse-Bolsonaro-discardsweaknesses-in-the-Brazilian-sns-564319.

Tetsuya, K. (2000). The Effects of Monetary and Fiscal Policy on Aggregate Demand in a Small Open Economy: An Application of the Structural error Correction Model, IMF Working Paper. Worldometers, 2020. Retrieved August 10, 2020 from https://www.worldometers.info/coronavirus/worldwide-graphs/. 